Article

\title{
Experimental Investigation of Consolidation Properties of Nano-Bentonite Mixed Clayey Soil
}

\author{
Gang Cheng ${ }^{1,2}$, Hong-Hu Zhu ${ }^{2, * \mathbb{D}}$, Ya-Nan Wen ${ }^{2,3}$, Bin Shi ${ }^{2}$ and Lei Gao ${ }^{4}$ \\ 1 School of Computer Science, North China Institute of Science and Technology, Beijing 101601, China; \\ chenggang@ncist.edu.cn \\ 2 School of Earth Sciences and Engineering, Nanjing University, Nanjing 210023, China; \\ sdsjs@cdg.com.cn (Y.-N.W.); shibin@nju.edu.cn (B.S.) \\ 3 Tunnel Design Institute, China Design Group Co., Ltd., Nanjing 210014, China \\ 4 Key Laboratory of Ministry of Education for Geomechanics and Embankment Engineering, Hohai \\ University, Nanjing 210098, China; gaoleihhu@hhu.edu.cn \\ * Correspondence: zhh@nju.edu.cn; Tel.: +86-025-89681137
}

Received: 11 July 2019; Accepted: 26 November 2019; Published: 7 January 2020

\begin{abstract}
As a new soil improvement method, adding nano-bentonite can enhance the engineering properties of soil. To study the stabilization effect of nano-bentonite on soil consolidation properties, a series of one-dimensional odometer tests were conducted on a clayey soil with different nano-bentonite mixing contents (i.e., $0.5 \%, 1 \%, 1.5 \%$, and $2 \%$ ). The effects of nano-bentonite on the coefficient of consolidation and permeability of the test soil were analyzed. The results show that adding a certain amount of nano-bentonite does not significantly affect the original consolidation characteristics of soil samples, but displays a notable effect on accelerating water drainage. Among all the soil samples, when the nano-bentonite mixing content is $0.5 \%$, the final compression amount is the largest and the final void ratio is the smallest. The coefficients of consolidation and permeability increase with increasing nano-bentonite mixing content under high stress state. The test results indicate that nano-bentonite can facilitate internal cementation of soil particles, which effectively reduces the compressibility of clayey soil.
\end{abstract}

Keywords: nano-bentonite; clayey soil; consolidation; compressibility; permeability

\section{Introduction}

Natural clayey soils rarely meet the requirements of modern geotechnical engineering projects in terms of bearing capacity of their foundations. As more and more high-rise buildings and massive structures are being built in developing countries such as China, effectively improving the strength and stiffness of a natural clay foundation is urgently required in geotechnical engineering practices. Vidal first proposed the concept of soil modification in the 1960s [1]. This technology has been developed rapidly and is now widely used in roadbeds, retaining walls, anti-seismic infrastructures, and other fields [2-4].

In general, a variety of reinforcing or treatment materials can be added to foundation soils to modify or improve their strength and deformation properties [5-9]. Such materials are divided into three types: inorganic binders, ionic soil stabilizing agents, and composite curing agents. Among various solidified materials, inorganic binders (e.g., cement, lime, fly ash, and their mixtures) are widely used for chemical modification of soils [10]. When inorganic binders are mixed in the soil, hydrolysis, hydration, and ion exchange occur. For instance, the addition of cement will increase the cohesion between soil particles, and greatly reduce the void ratio, improving the structural strength. However, the use of cement to reinforce soil is limited by the soil type. Because the organic matter 
has an adverse effect on the cementation process of soil, it is not appropriate for soils rich in organic matter [11]. In addition, the production of cement is an intensive carbon-emission process that has negative environmental impacts [12,13]. The strength of lime treated soil develops slowly and its water stability is relatively weak. Another major disadvantage of this method is that it increases soil brittleness [14]. The strength of soil modified with lime-fly ash is poor at the early stage, which directly affects the progress and quality of construction. A relatively high strength can be achieved in at least 28 days, and the longer the time available, the higher the strength becomes. It can be concluded that the traditional soil modification materials have certain disadvantages and cannot fully meet engineering needs.

Hollister et al. found that changes in the surface area and volume of material lead to some changes in its physical properties when the particle size of the material is reduced from micron to nanometer [15]. Therefore, more and more researchers began to study nanomaterials. These materials have been popularized and applied in metal smelting, chemical industry, microelectronics, medicine, and biology, which are known as "the most promising materials in the 21st century" [16]. Nanomaterials are a kind of ultra-fine material with a large specific surface area and a 1-100 nm particle size. They have some special structural characteristics, with four major effects: the size effect, quantum effect, surface effect, and interface effect [17]. With the wide application of nanomaterials, their cost has sharply decreased, providing the possibility for large-scale application of nanomaterials in geotechnical engineering.

Norazlan et al. carried out a series of experiments to study the geotechnical properties of nano-kaolin mixed soil (most of the nano-kaolin sizes are between 39 d.nm and 70 d.nm), and found that the basic properties and engineering characteristics of soils are significantly affected by the addition of a small amount of nanoparticles [18]. Recently, researchers in Malaysia [19-21], India [22], Egypt [23], and other countries conducted a series of experimental studies in this field. These studies mainly focused on the influence of nanomaterials on the compressive, tensile, and shear strengths of soil. The results show that the soil mixed with nano-clay displayed a higher strength than the original one. With the increase in nanomaterial content, the strength of soil does not increase continually but rather shows as a curve with a peak inflection point. To explain the micro-mechanism of nanomaterials modified soil, Mostafa et al. conducted an experimental study [24]. In this study, a different percent of nano-clay montmorillonite was used in order to check out the created changes in soil characteristics with an increasing percentage of nano-clay. Based on the study, they found that the cohesion of soil increased gradually with the filling of soil voids after the incorporation of nanoparticles, according to the results of scanning electron microscopy (SEM). Gao et al. investigated the unconfined compressive strength of clay mixed with nano-MgO (the soil moisture content was $10 \%$ and soil dry density was $1.5 \mathrm{~g} \cdot \mathrm{cm}^{-3}$, the different dosages of nano-MgO, i.e., $0 \%, 2 \%, 4 \%$, and $6 \%$ were put into the soil samples) and nano- $\mathrm{Al}_{2} \mathrm{O}_{3}$, respectively $[25,26]$. They were found to have a profound physical and chemical influence on the soil samples. The above research results mainly focus on the contribution of nanomaterials to the improvement of soil strength, whereas studies of the consolidation, permeability, compression, and other characteristics of soil mixed with nanomaterials are lacking, and their action mechanisms are not clear. Wang et al. completed one-dimensional (1D) compression tests of nano-MgO modified cement-soil with different mixing ratios, and demonstrated that the compressive deformation of modified cement-soil gradually decreased with the increase in nano-MgO mixing ratio. $\mathrm{Ng}$ et al. studied the change in the permeability of clay after adding different amounts of nano-oxides (two different nanomaterials namely gamma-aluminum oxide powder $\left(\gamma-\mathrm{Al}_{2} \mathrm{O}_{3}\right)$ and nano-copper oxide $(\mathrm{CuO})$ were selected and mixed with clay at different percentages (i.e., $2 \%, 4 \%$, and 6\%)) [27]. They found that with the increase in nano-oxides content, the void of clay was filled with nanomaterials and the permeability coefficient decreased. Neethu et al. studied the effect of nano-clay on the consolidation and permeability of laterite and kaolinite [22]. They found that when the content of nano-clay was $1 \%$, the consolidation and permeability coefficients of laterite and kaolinite decreased significantly. To compensate for the long duration of the conventional drainage consolidation method, $\mathrm{Li}$ used the electro-osmosis method to study the consolidation characteristics and studied the influence 
of nano-montmorillonite on the electro-osmosis and mechanical properties of soil [28]. It is found that nano-montmorillonite can effectively improve the shear strength of soil, but has no effect on the electro-osmosis drainage of soil. As an anti-seepage cushion material, under a larger engineering load, nanomaterial-modified clay inevitably produces certain compression deformation, which affects the anti-seepage and anti-fouling performance. In addition, the replacement of cement by clay offers lower life-cycle carbon footprint as clay is a natural resource. Therefore, this can result in reduced emissions of $\mathrm{CO}_{2}$ and is a more sustainable approach compared with soil-cement solidification [29-32].

In this paper, a series of one-dimensional (1D) consolidation tests were conducted on clayey soil with different nano-bentonite mixing contents. Based on the test results, the compression, consolidation, and permeability characteristics of the soil samples after adding nano-bentonite were systematically investigated.

\section{Materials and Methods}

\subsection{Test Materials}

The soil samples used in this experiment were collected at the depth of $2 \mathrm{~m}$ along the Yangtze River in Qixia District, Nanjing, China. The basic physical and mechanical parameters of the soil are listed in Table 1. The grain size distribution was determined by sieve analysis and hydrometer analysis, which is shown in Figure 1. The natural moisture content was obtained by using the drying method. The liquid and plastic limit tests were conducted in accordance with ASTM standard D4318. By performing standard Proctor compaction tests according to ASTM standard D698, the optimum moisture content and maximum dry unit weight of the soil were obtained. According to the Classification and codes for Chinese soil (GB/T 17296-2009) [33], the test soil is classified as silty clay with medium plasticity. In order to study the mineral composition in the soil, X-ray Diffraction (XRD) analysis of the soil sample were carried out. As shown in Figure 2, the mineral components in the test soil are mainly composed of quartz, kaolin, montmorillonite, muscovite, illite, chlorite, and calcite. Some clay minerals will absorb water during the test, which leads to a decrease in the soil permeability.

Table 1. Basic parameters of the test soil.

\begin{tabular}{|c|c|c|c|c|c|c|c|c|}
\hline \multirow{2}{*}{$\begin{array}{l}\text { Specific } \\
\text { Gravity }\end{array}$} & \multicolumn{3}{|c|}{ Soil Particle Fraction (\%) } & \multirow{2}{*}{$\begin{array}{c}\begin{array}{c}\text { Natural Moisture } \\
\text { Content }\end{array} \\
(\%) \\
\end{array}$} & \multirow{2}{*}{$\begin{array}{l}\text { Liquid } \\
\text { Limit } \\
(\%)\end{array}$} & \multirow{2}{*}{$\begin{array}{l}\text { Plastic } \\
\text { Limit } \\
(\%)\end{array}$} & \multirow{2}{*}{$\begin{array}{l}\text { Maximum Dry } \\
\text { Unit Weight } \\
\left(\mathrm{g} \cdot \mathrm{cm}^{-3}\right)\end{array}$} & \multirow{2}{*}{$\begin{array}{l}\text { Optimum } \\
\text { Moisture } \\
\text { Content (\%) }\end{array}$} \\
\hline & Clay & Silt & Sand & & & & & \\
\hline 2.73 & 34 & 59 & 7 & 3.4 & 43.6 & 28.1 & 1.52 & 26.0 \\
\hline
\end{tabular}

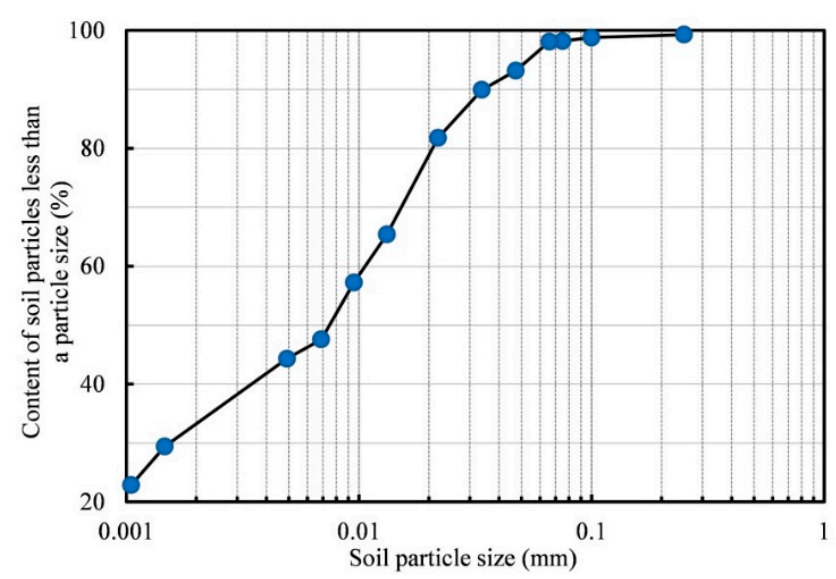

Figure 1. Grain size distribution of the test soil. Blue dots represent the content of soil particles less than a particle size $(\%)$. 


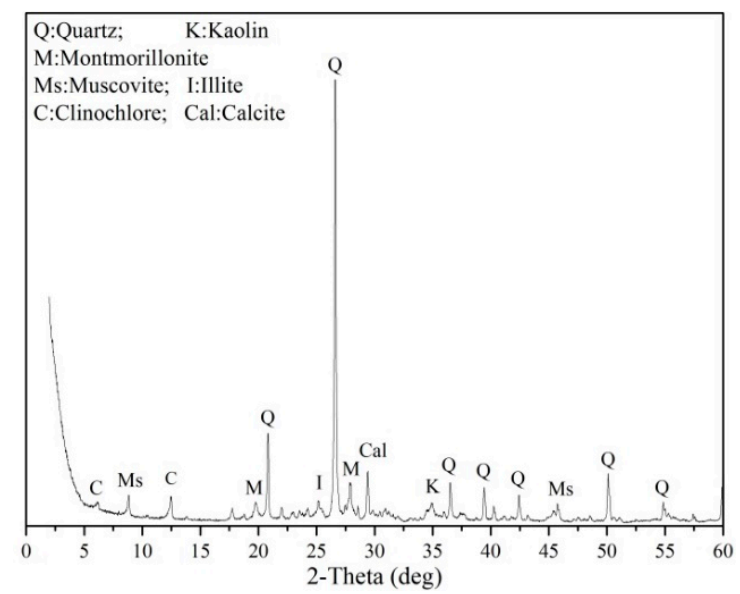

Figure 2. X-ray Diffraction results of the test soil.

The nanomaterial used in the experiments was high-purity nano-bentonite. It is a kind of fine white powder with high hydrophilicity and a large specific surface area (SSA). This nano-bentonite is produced by Zhejiang Fenghong New Material Co. Ltd. (Huzhou, China). The properties of the nano-bentonite are as follows: the specific gravity is 1.8; over $97 \%$ of soil particles are smaller than $74 \mu \mathrm{m}$; the bulk density is less than $0.3 \mathrm{~g} / \mathrm{cm}^{3}$; the SSA is $750 \mathrm{~m}^{2} / \mathrm{g}$; the Cation Exchange Capacity (CEC) is $90 \mathrm{~mol} / 100 \mathrm{~g}$; the interlayer spacing $\mathrm{d}_{001}$ determined using XRD is $2.2 \mathrm{~nm}$.

\subsection{Test Method}

Four nano-bentonite mixing contents $(0.5 \%, 1 \%, 1.5 \%$, and $2 \%, \mathrm{w} / \mathrm{w})$ were selected in this study. These four percentages were determined referring to the literature on soil stabilizing methods [34]. The preparation method of the soil sample was as follows: the air-dried soil sample was crushed and sieved through a 2-mm sieve. Then, the nano-bentonite, as set above, was evenly mixed with the soil. After the nano-bentonite was dispersed, de-aired water was added to the soil sample, which was packed in a plastic bag and placed in the humidifier for $24 \mathrm{~h}$ to distribute the water evenly in the soil sample. The static compaction method was used for preparing the soil samples at the maximum dry density. The soil samples were then fully saturated in a vacuum chamber. Afterward, the 1D consolidation test was conducted according to ASTM standard D2435.

The instrument used in the tests was the WG-1C triple high-pressure oedometer, produced by Nanjing Ningxi Soil Instrument Co. Ltd. (Nanjing, China). The cross-sectional area of the sample was $30 \mathrm{~cm}^{2}$ and the height was $2 \mathrm{~cm}$. The multi-stage loading method was adopted with double drainage condition. The load sequence of the consolidation test was $25 \mathrm{kPa}, 50 \mathrm{kPa}, 100 \mathrm{kPa}, 200 \mathrm{kPa}, 400 \mathrm{kPa}$, $800 \mathrm{kPa}, 1200 \mathrm{kPa}, 1600 \mathrm{kPa}, 2400 \mathrm{kPa}$, and $3200 \mathrm{kPa}$. In accordance with the Standard of Geotechnical Test Method [35], the samples were loaded step by step and each loading lasted for $24 \mathrm{~h}$ until the test was completed. The soil compression varying with time under each load were automatically collected by the displacement sensor. Foreign scholars had compared the strength of the soil samples at curing period of 1,7, 14, 28 days, and found that the soil samples with different nanomaterial contents showed a similar trend of strength change: the greater the curing time, the higher the strength [36]. The main purpose of this study was to investigate the consolidation characteristics of clayey soil mixed with nano-bentonite. Relevant results are expected to be applied to the rapid in-situ modification of clayey soil. Therefore, the test samples were designed with one day curing time. In the next step study, the influence of curing time on the strength of soil samples will be systematically analyzed. 


\section{Results and Discussion}

\subsection{Compression Characteristics}

The compression curve reflects the deformation characteristics of soil under loading, which is important for settlement prediction. Figure 3 shows the relationship between the compression and consolidation pressure of the soil samples. It is found that the curve shapes of the soil compression with variations in consolidation pressure are similar, irrespective of whether nano-bentonite is added or not. The relationship between final compression and nano-bentonite mixing content is plotted in Figure 4 . The final compression of samples without nano-bentonite is the smallest, which is $5.2 \mathrm{~mm}$. When the nano-bentonite mixing content is about $0.5 \%$, the final compression of the soil sample reaches a peak value of $5.6 \mathrm{~mm}$. When the nano-bentonite mixing content is higher, the compressibility decreases, but the final compression of the four groups of samples with nano-bentonite is larger than that of samples without nano-bentonite. For all the nano-bentonite mixed soil samples, the final compression is the smallest when the nano-bentonite mixing content is $2 \%$. However, this value is still $5.2 \%$ higher than that of the samples without nano-bentonite. This shows that the final compression of the clayey soil is significantly enhanced by adding a small amount of nano-bentonite. The strength of the test sample increases with the addition of nano-bentonite, but at the same time, the settlement becomes larger. Thus, when this method was used to improve soil properties, its adverse effect on settlement need to be carefully considered. Meanwhile, the addition of nano-bentonite may cause a variation in permeability of the test samples, which will be discussed in the following part.

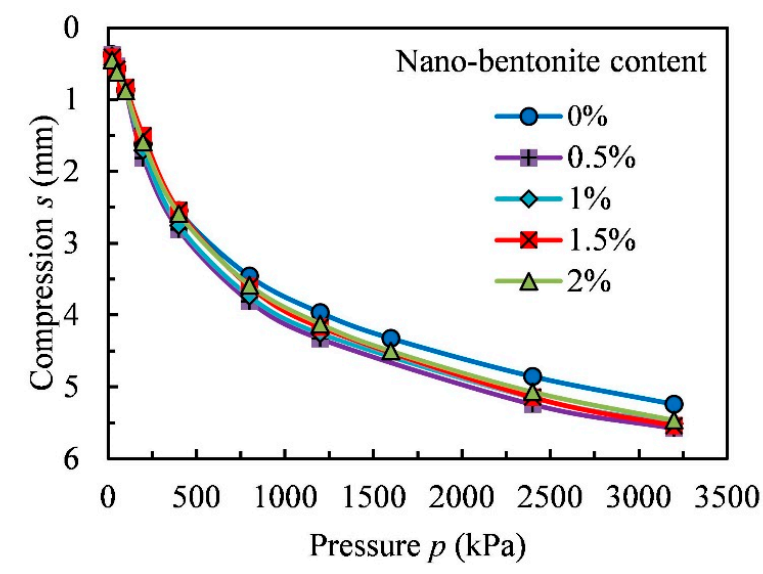

Figure 3. Curves of compressive deformation $s$ versus consolidation pressure $p$.

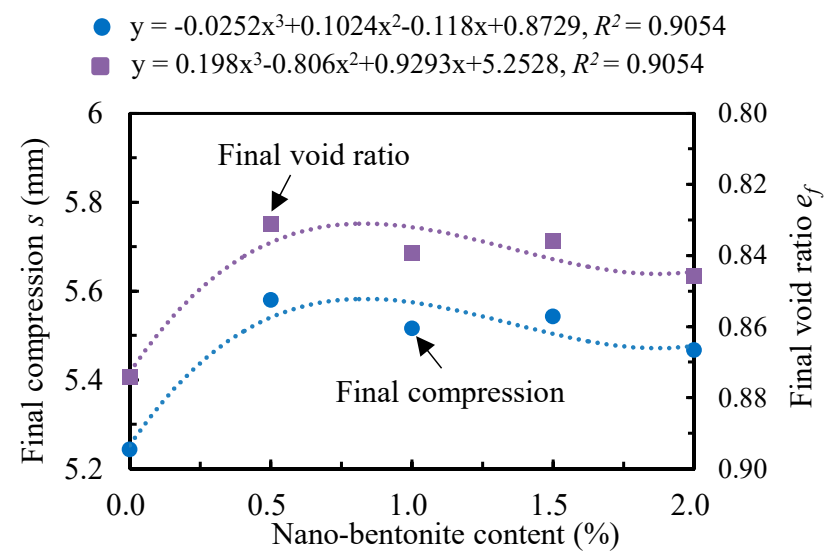

Figure 4. Relationship of different nano-bentonite mixing contents versus compressive deformation $s$ and different nano-bentonite mixing contents versus void ratio $e_{f}$. 
From Figure 4, it can be seen that the influence of the nano-bentonite mixing content on the final void ratio of clayey soil is significant. When the nano-bentonite mixing content is $0.5 \%$, the final void ratio of the samples with nano-bentonite reaches its lowest value, and the final void ratio of nano-bentonite mixed clayey soil is smaller than pure soil. This indicates that the addition of a small amount of nano-bentonite can fill the voids between clay particles, therefore, the void ratio of clayey soil decreases.

The $e-p$ ( $e$ represents the soil void ratio, and $p$ represents the effective pressure) and $e-\lg p(e$ represents the soil void ratio, $\lg p$ represents the logarithm of effective pressure) curves in Figures 5 and 6, respectively, show that the relationship between the void ratio and consolidation pressure is basically the same irrespective of the nano-bentonite mixing content addition. The compression index is calculated to be 0.404 . With the increase in pressure, the soil void ratio decreases gradually. When the consolidation pressure is high, the decreasing trend of the soil void ratio slows down. Figure 6 shows that the initial stage of the curve drops in a gentle parabola tendency, and the back part exhibits a linear correlation with a certain slope. Curve fitting is conducted on the four groups of data, where the fitting curve of soil without nano-bentonite added is $y=-0.165 \ln x+2.21$. When the nano-bentonite mixing content is $0 \%, 0.5 \%, 1 \%, 1.5 \%$, and $2 \%$, the corresponding slope of fitting curve is $0.165,0.169,0.173$, 0.185 , and 0.177 , respectively. When the nano-bentonite mixing content is $1.5 \%$, the value of the curve slope reaches the maximum, which shows that the compressibility of soil is high. The pre-consolidation pressure calculated from the $e-\lg p$ curve is $99.75 \mathrm{kPa}$ [37].

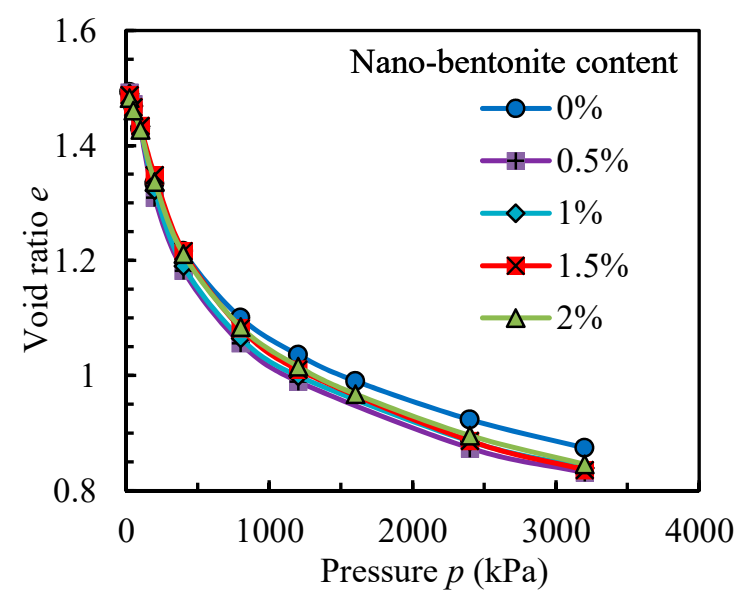

Figure 5. $e-p$ curves for clayey soil with different nano-bentonite mixing contents added. $e$ represents the void ratio of the soil, while $p$ represents the effective pressure.

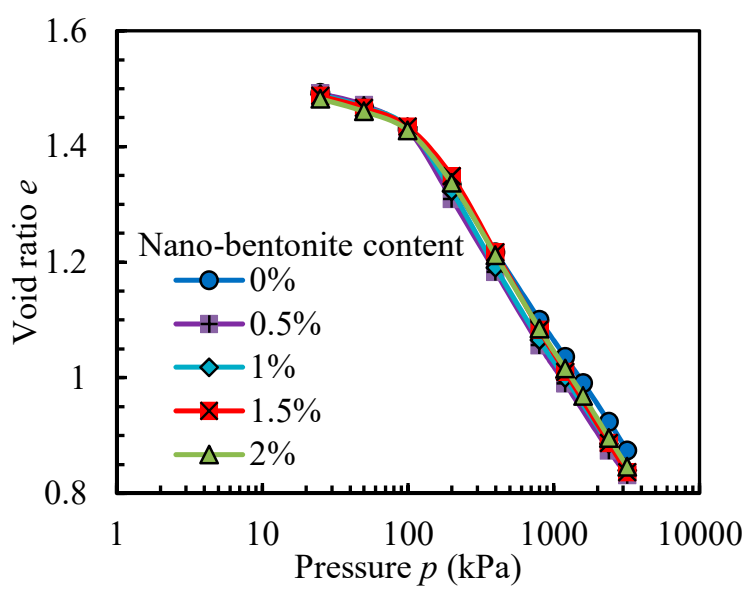

Figure 6. $e-\lg p$ curves for clayey soil with different nano-bentonite mixing contents added. $e$ represents the void ratio of the soil, while $\lg p$ represents the logarithm of effective pressure. 
The compression coefficient is one of the critical parameter used to characterize soil compressibility. Compression coefficients of the test soil in various pressure ranges were calculated according to the $e-p$ curves. Table 2 shows that the compression coefficient varies from 0.053 to 0.972 . When the applied consolidation pressure was relatively small, both the void ratio and the compression coefficient varied considerably with the nano-bentonite mixing content. With the increase in pressure, the void ratio of the test soil decreased and the compression coefficient also reduced accordingly; however, the influence of nano-bentonite mixing content on the compression coefficient is relatively small. The main reason is that the soil voids at low pressures are relatively large, and therefore the addition of nano-bentonite has a significant influence on the result. While at high pressures, the soil samples were compacted tightly, and effect of the nano-bentonite on compression coefficient is significantly weakened.

Table 2. Coefficient of compressibility changes with the consolidation pressure. The unit of the compression coefficient is $\mathrm{MPa}^{-1}$.

\begin{tabular}{ccccccccc}
\hline \multirow{2}{*}{$\begin{array}{c}\text { Nano-Bentonite } \\
\text { Mixing Content (\%) }\end{array}$} & $\mathbf{7}$ Consolidation Pressure (kPa) \\
\cline { 2 - 9 } & $\mathbf{2 5 - 5 0}$ & $\mathbf{5 0 - 1 0 0}$ & $\mathbf{1 0 0 - 2 0 0}$ & $\mathbf{2 0 0 - 4 0 0}$ & $\mathbf{4 0 0 - 8 0 0}$ & $\mathbf{8 0 0 - 1 2 0 0}$ & $\mathbf{1 2 0 0 - 2 4 0 0}$ & $\mathbf{2 4 0 0 - 3 2 0 0}$ \\
\hline 0 & 0.972 & 0.778 & 0.950 & 0.590 & 0.290 & 0.161 & 0.099 & 0.062 \\
0.5 & 0.813 & 0.851 & 1.199 & 0.632 & 0.317 & 0.166 & 0.097 & 0.053 \\
1.0 & 0.843 & 0.709 & 1.107 & 0.661 & 0.314 & 0.164 & 0.095 & 0.058 \\
1.5 & 0.843 & 0.650 & 0.855 & 0.661 & 0.335 & 0.180 & 0.103 & 0.063 \\
2.0 & 0.880 & 0.660 & 0.905 & 0.629 & 0.317 & 0.171 & 0.105 & 0.063 \\
\hline
\end{tabular}

It can be seen from Figure 4 that the effect of nano-bentonite mixing content on the change of the final void ratio of clayey soil is basically the same as that on the final compression amount, that is, the final void ratio of clayey soil with nano-bentonite is smaller than that of the samples without nano-bentonite, and the minimum void ratio of the soil samples without nano-bentonite is 0.87 . When the nano-bentonite mixing content is $0.5 \%$, the change of void ratio reaches the peak value, which is $0.83,4.6 \%$ lower than that of the soil samples without nano-bentonite. And in the clayey soil with nano-bentonite, the maximum void ratio is 0.85 , it is still $2.3 \%$ lower than that without nano-bentonite. At the same time, the addition of a small amount of nano-bentonite will fill the voids between the soil particles, thus reducing the clayey soil void ratio. Figure 4 shows that after the addition of nano-bentonite, as there is an increase of consolidation pressure, the final compression of the test soil increases, and the final void ratio decreases. This is because the addition of nano-bentonite changes the cohesion between clay particles, reduces the number and size of voids between soil particles, alters the soil microstructure, and thus improves the ability of clay to resist compressive deformation. The specific reason for this effect is that the nano-bentonite particles are very small, and the surface lattice structure is different from conventional materials. When it is mixed into the soil, the soil particles are combined and voids are filled, it will change the adhesion characteristics of soil particles, and form new cementation between soil particles, as shown in Figure 7. The improvement of the microstructure can effectively improve the strength of the soil.

\subsection{Consolidation Characteristics}

The coefficient of consolidation is a parameter reflecting the drainage rate of soil during consolidation. According to the relationship between soil compression and time that acquired in the test, the coefficient of consolidation of samples with different nano-bentonite mixing contents under various loads can be obtained by using the time square root method [38], as shown in Figure 8. It is found that the coefficient of consolidation of the test soil varies in the range of $6.9 \times 10^{-3}$ to $1.8 \times 10^{-1} \mathrm{~cm}^{2} \cdot \mathrm{s}^{-1}$. Under lower pressure, the coefficient of consolidation of the test soil decreases remarkably with the increase in pressure, range from about $1.4 \times 10^{-1}$ to $2.8 \times 10^{-2} \mathrm{~cm}^{2} \cdot \mathrm{s}^{-1}$. As the pressure continues to increase, the coefficient of consolidation of the test sample decreases slightly. The relationship between coefficient of consolidation and void ratio is investigated, as shown in Figure 9. The results show that the coefficient of consolidation of the soil sample decreases sharply 
with the decrease in void ratio. At the void ratio of 1.5 1.3, the reduction rate of the coefficient of consolidation is very significant.

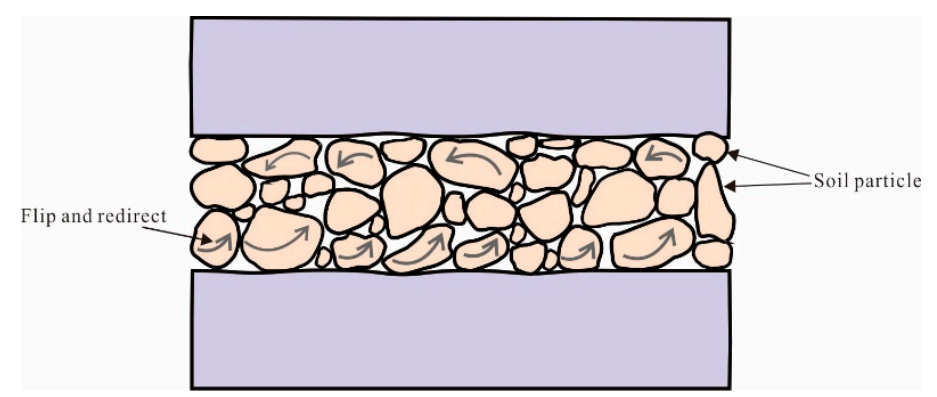

(a)

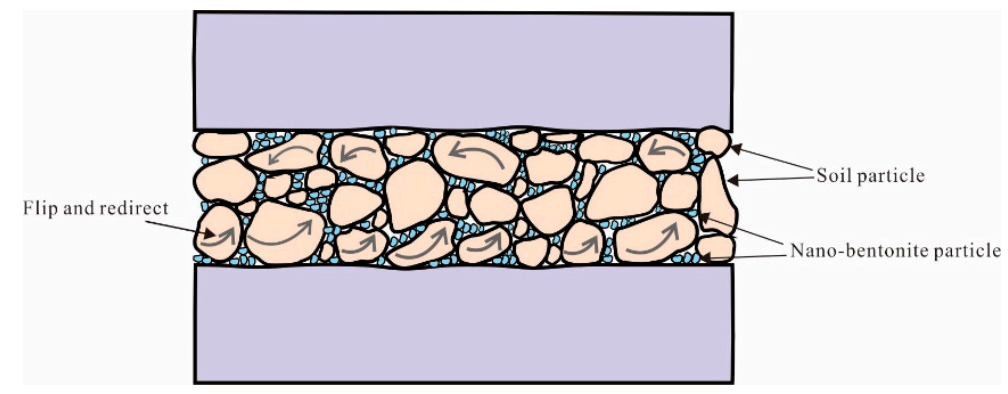

(b)

Figure 7. Filling effect and interaction between soil particles: (a) without nano-bentonite added, and (b) with nano-bentonite added.

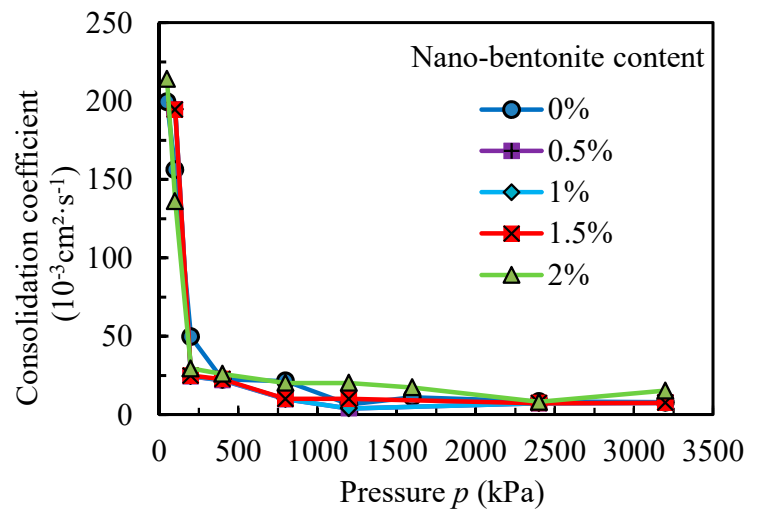

Figure 8. Curves of the coefficient of consolidation versus consolidation pressure.

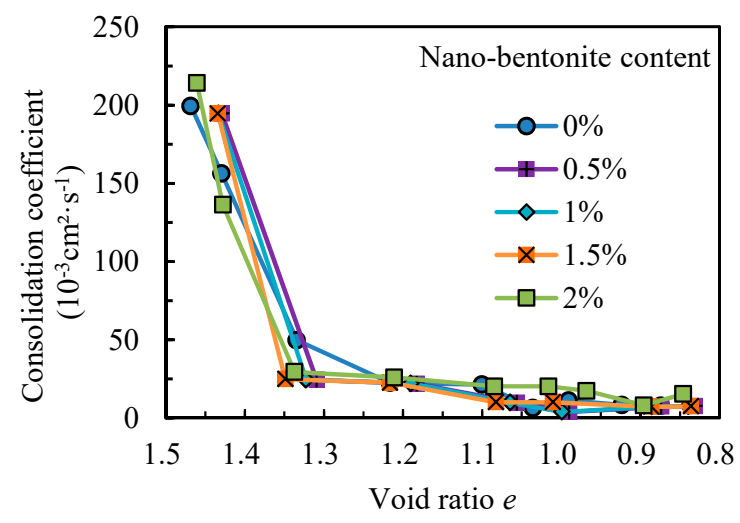

Figure 9. Curves of the coefficient of consolidation versus the void ratio. 
Taking the consolidation pressure of $1800 \mathrm{kPa}$ as an example, the influence of nano-bentonite mixing content on the coefficient of consolidation of the test soil was further studied, as shown in Figure 10. For other pressures, the phenomenon is not as obvious as the $1800 \mathrm{kPa}$ pressure, but the pattern is similar. The results show that when the nano-bentonite mixing content is between $0.5 \%$ and $2 \%$, the curve shows a non-linear increasing trend with the increase in nano-bentonite mixing content. When the nano-bentonite mixing content is $2 \%$, the consolidation rate of clayey soil is the largest, and the coefficient of consolidation is about 2.14 times larger than the sample with $0.5 \%$ nano-bentonite mixing content. In the consolidation test, the coefficient of consolidation of the sample without nano-bentonite was $8.7 \times 10^{-3} \mathrm{~cm}^{2} \cdot \mathrm{s}^{-1}$, which is $6.6 \times 10^{-3} \mathrm{~cm}^{2} \cdot \mathrm{s}^{-1}$ lower than that of the sample with $2 \%$ nano-bentonite mixing content. It seems that the consolidation rate is lower than that of pure soil, except for the soil with $2 \%$ nano-bentonite mixing content. This shows that adding an appropriate nano-bentonite mixing content to the soil can accelerate the consolidation rate. Compared with pure soil, when the nano-bentonite mixing content is less than $1.5 \%$, the soil permeability is smaller. If the nano-bentonite mixing content is $2 \%$, the permeability coefficient will be larger.

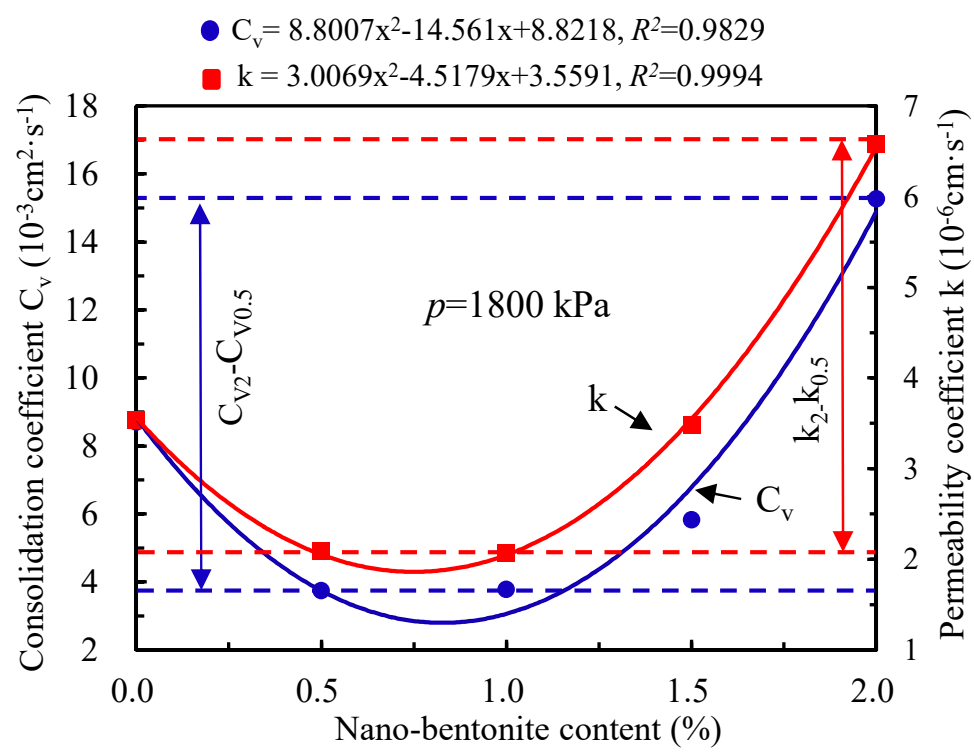

Figure 10. Relationships of the coefficient of consolidation $C_{v}$ and the permeability coefficients $k$ with different nano-bentonite mixing contents. $\mathrm{C}_{\mathrm{v}}$ is the coefficient of consolidation of soil, $\mathrm{C}_{\mathrm{v} 0.5}$ (or $\mathrm{C}_{\mathrm{v} 2}$ ) means the coefficient of consolidation of soil with the nano-bentonite mixing content of $0.5 \%$ (or $2.0 \%$ ). $\mathrm{k}$ is the permeability coefficient of clay, $\mathrm{k}_{0.5}$ ( or $\mathrm{k}_{2}$ ) means the permeability coefficient of soil with the nano-bentonite mixing content of $0.5 \%$ (or $2.0 \%$ ). $P$ is the consolidation pressure.

\subsection{Secondary Consolidation Characteristics}

For clayey soil, secondary consolidation is significant, which will lead to large post-construction settlement in engineering practices. The long-term foundation settlement due to secondary consolidation cannot be ignored in most cases. In terms of mechanism, the secondary consolidation of clayey soil is a slow deformation process caused by creeping of bound water film on the soil particle surface and the rearrangement of soil particles. This phenomenon usually occurs when the excess pore water pressure is fully dissipated, and the effective pressure is substantially stable.

The coefficient of secondary consolidation of soil can be calculated from the slope of the back section of the curve of void ratio versus log time. Figure 11 shows the coefficient of secondary consolidation of the test soil with different nano-bentonite mixing contents. It is shown that the coefficient of secondary consolidation varies from $0.3 \times 10^{-3}$ to $8.9 \times 10^{-3}$, and its law of change with consolidation pressure is as follows: when the consolidation pressure is less than $500 \mathrm{kPa}$, the coefficient of secondary consolidation increases significantly with the increase in pressure; when the 
consolidation pressure is greater than $500 \mathrm{kPa}$, the coefficient of secondary consolidation varies within a small range with the increase of consolidation pressure. This is because when the consolidation pressure is low, as the pressure increases, the consolidation deformation of the clayey soil becomes less obvious, whereas the secondary consolidation effect gradually dominates the deformation process. However, as the pressure continues to increase, the clayey soil is tightly compacted, and therefore the secondary consolidation is weakened.

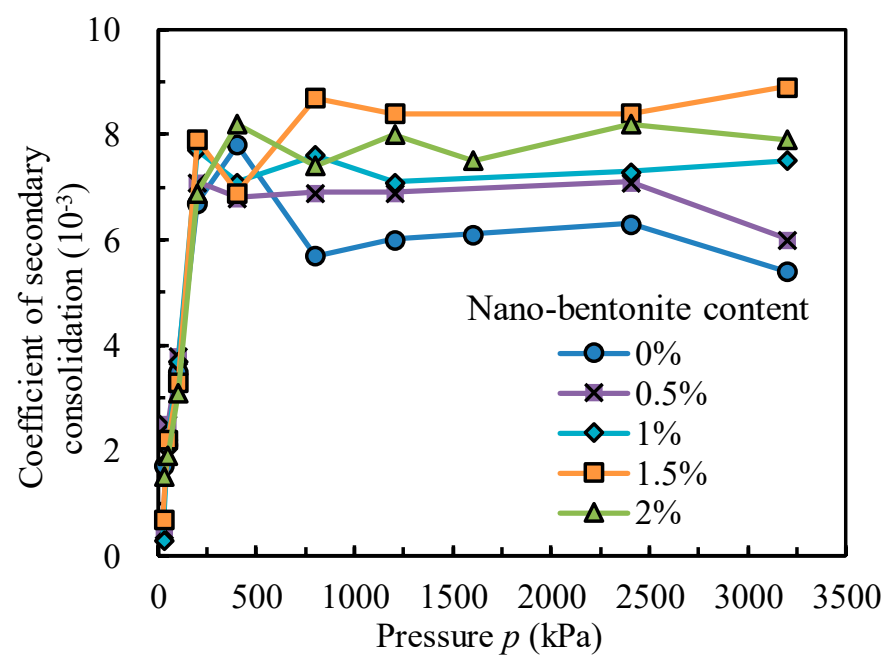

Figure 11. Curves of the coefficient of secondary consolidation versus the void ratio.

The relationship between the nano-bentonite mixing content and the coefficient of secondary consolidation is shown in Figure 12. Under high pressure condition, the addition of nano-bentonite in clayey soil has a significant effect on the coefficient of secondary consolidation. With the increase in the nano-bentonite mixing content, the coefficient of secondary consolidation increases continuously and reaches its peak value when the nano-bentonite mixing content is $1.5 \%$. This indicates that the size and shape of voids in the clayey soil may change due to the physical filling effect of nano-bentonite particles. The rearrangement of the soil structure and creeping of the bound water film in the nano-bentonite mixed soil are slower that the pure soil in the secondary consolidation stage. Indeed, this effect is not obvious at the pressure of $500 \mathrm{kPa}$ or lower, which may be due to the fact that under low pressures, the nano-bentonite particles have little effect on the soil skeleton.

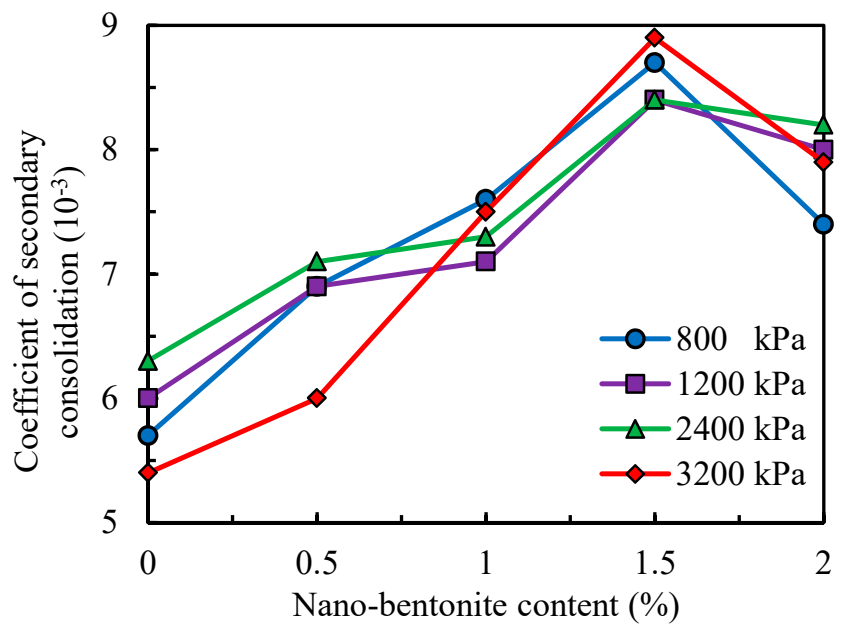

Figure 12. Curves of the coefficient of secondary consolidation versus nano-bentonite mixing content. 


\subsection{Permeability}

Soil permeability has an essential influence on the consolidation and strength of soil, which will seriously affect the safety of geotechnical infrastructures. Therefore, it is necessary to study the permeability of nano-bentonite mixed soil. According to Terzaghi's one-dimensional consolidation theory [39], the relationship between the permeability coefficient and coefficient of consolidation is

$$
k=\frac{C_{v} \gamma_{w} a_{v}}{1+e_{0}}
$$

where $k$ is the permeability coefficient of the soil, $a_{v}$ is the compressibility coefficient, $e_{0}$ is the initial void ratio of soil, and $\gamma_{w}$ is the specific weight of water. All the samples show similar behavior, independent of the additive content. The permeability coefficient obtained from Equation (1) was used to study the permeability with nano-bentonite mixed soil.

Figure 13 shows the variation of permeability coefficient with the change in consolidation pressure. It is found that the permeability coefficient varies in the order of $10^{-6}$ to $10^{-4} \mathrm{~cm} \cdot \mathrm{s}^{-1}$, and is greatly influenced by consolidation pressure. In the whole test process, the permeability coefficient decreases with the increase in consolidation pressure. It is also found that the permeability coefficient of the clayey soil samples decreases significantly when the consolidation pressure is low, ranging from $4.5 \times 10^{-4}$ to $6 \times 10^{-5} \mathrm{~cm} \cdot \mathrm{s}^{-1}$. As the pressure continues to increase, the permeability coefficient tends to stabilize.

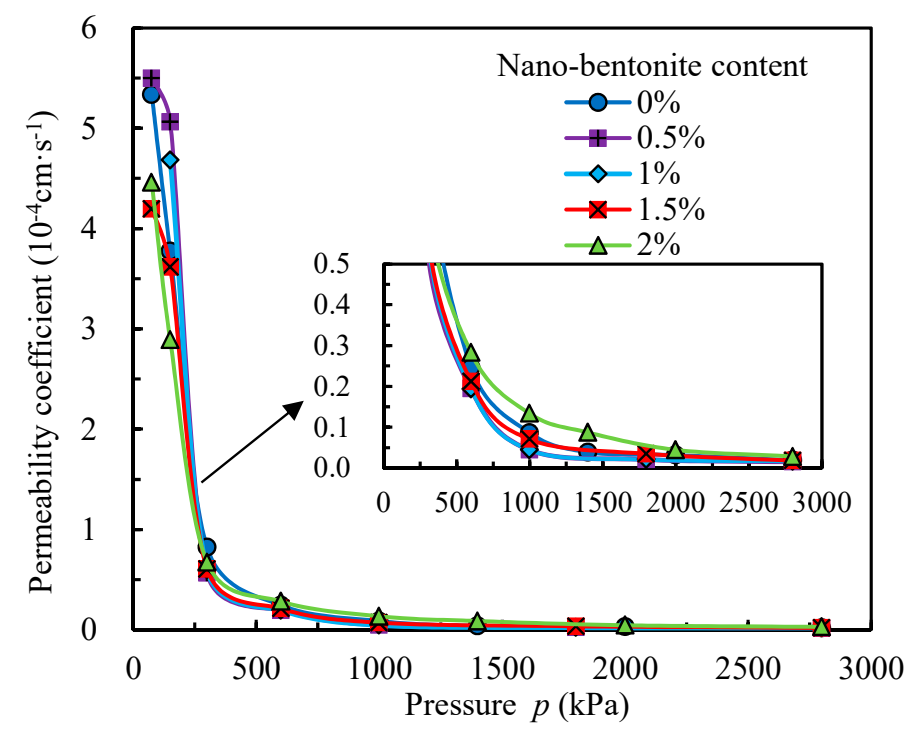

Figure 13. Curves of the permeability coefficient versus consolidation pressure. The small graph in the figure is an enlargement of the Y-axis in the range of $0-0.5$.

The soil permeability is closely related to its void ratio. As shown in Figure 14, the permeability coefficient significantly reduces with the decrease of the void ratio. By fitting the $e-\lg k$ curve, it is found that the relationship between the void ratio $e$ and logarithm of permeability coefficient is approximately linear, which indicates that the void ratio plays a dominant role in affecting soil permeability [40]. At the nano-bentonite mixing content of $2 \%$, the linear relationship can be expressed as follows: $\ln k=$ $8.7275 e-4.27$. 


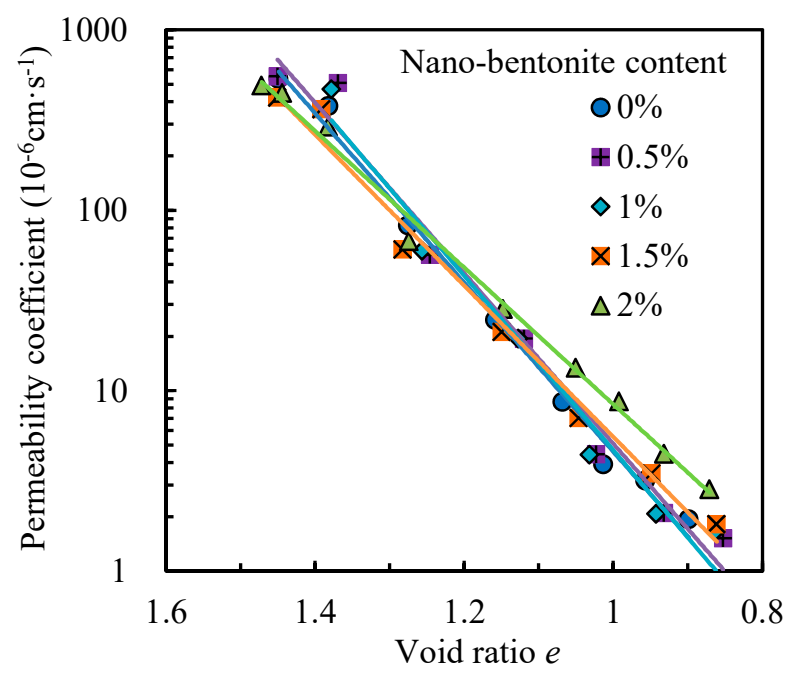

Figure 14. Curves of the permeability coefficient versus void ratio.

When the consolidation pressure is $1800 \mathrm{kPa}$, the influence of nano-bentonite on the permeability coefficient of the soil samples is shown in Figure 10. When the nano-bentonite mixing content is between $0.5 \%$ and $2 \%$, the influence of the nano-bentonite mixing content on the permeability coefficient is similar to that of the coefficient of consolidation. That is, with the increase in nano-bentonite mixing content, the curve of permeability coefficients shows a non-linear increasing trend. The permeability coefficient of clayey soil with $2 \%$ nano-bentonite mixing content is 3.15 times higher than that with $0.5 \%$ nano-bentonite mixing content. To better compare the influence of nano-bentonite on the permeability coefficient, the permeability coefficient results of soil with $0 \%$ and $2 \%$ nano-bentonite addition under low and high pressure ranges were presented in Figure 15. It is seen in Figure 15a that the permeability coefficient decreases with the addition of nano-bentonite at low consolidation pressures, while the difference becomes less obvious with the increase of pressure. The reason is because nano-bentonite particles have little effect on the soil skeleton under low pressure. At a higher pressure (more than $500 \mathrm{kPa}$ ), the permeability coefficient of nano-bentonite mixed soil is higher, which indicates that nano-bentonite contributes to permeability modification of soil.

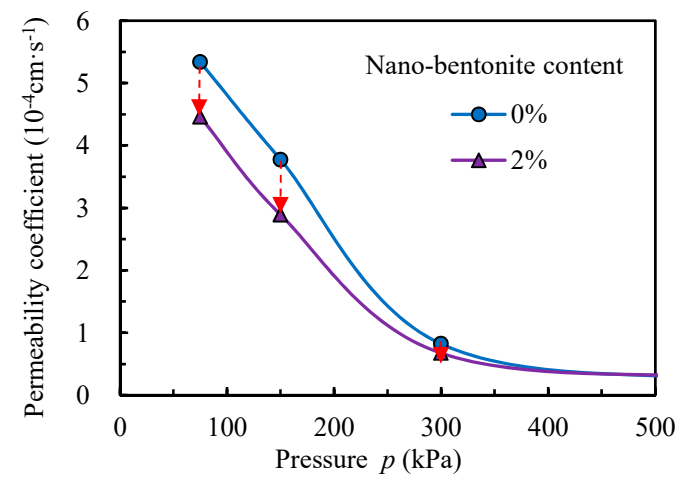

(a)

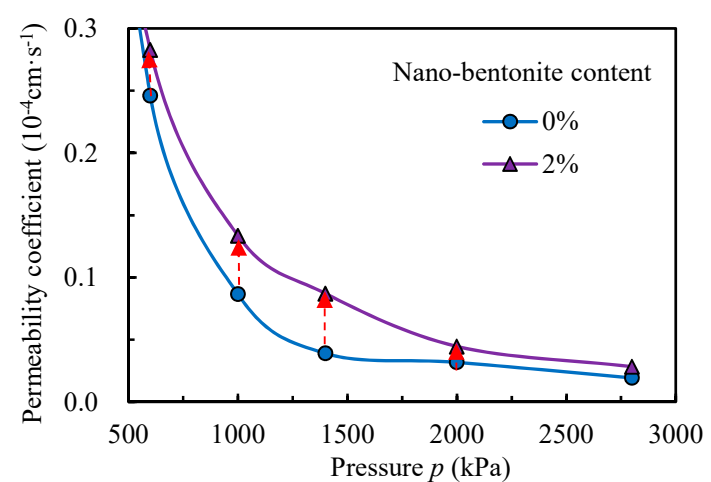

(b)

Figure 15. Curves of the permeability coefficient versus consolidation pressure: (a) permeability coefficient of soil with a consolidation pressure of $0-500 \mathrm{kPa}$, and (b) permeability coefficient of soil with a consolidation pressure of 500-3000 kPa.

Based on the above findings, it is concluded that, with the increase of consolidation pressure, the permeability coefficient of the clayey soil shows a decreasing trend. This is because under low consolidation pressure, the porous flow in the clayey soil is mainly dominated by free water and bound water. With the dissipated of pore water pressure, the void ratio changes significantly, resulting in a 
substantial change in the $k$ value. Under high consolidation pressure, the porous flow of clayey soil is mainly dominated by bound water. At this time, the pore water is hard to drain, showing a characteristic that the permeability change is small and tends to be stable. The influence of nano-bentonite on the permeability coefficient is as follows: when the nano-bentonite mixing content is $0.5 \%-2 \%$, the curve shows a non-linear increasing trend with the increase in the nano-bentonite mixing content. The permeability coefficient of the test soil with nano-bentonite is higher than the pure soil under high pressure. This is because adding nano-bentonite changes the bonding interaction between clay particles, forming new cementation between clay particles, playing a good bridge role, providing a new channel for water discharge, and promoting drainage consolidation [41]. Under high pressure, nano-bentonite bears, transfers, and disperses part of the pressure, and sufficient hydration and a hardening reaction occur between the clayey soil particles, which improves the hydration speed of the clay particles and is conducive to the drainage consolidation of the clay. Under low pressure, the results are different from high pressure. The effect of the nano-bentonite mixing content on the soil structure is only obvious under high pressure. When the pressure is low, the effect is not obvious.

\section{Conclusions}

In this paper, the one-dimensional consolidation characteristics of nano-bentonite mixed clayey soil were investigated through laboratory experiments. The influence of the nano-bentonite mixing content on the compression coefficient, coefficient of consolidation, coefficient of secondary consolidation, and permeability coefficient was analyzed. The following conclusions are drawn:

(1) Mixing $0.5 \%$ to $2 \%$ nano-bentonite into the clayey soil has little effect on the original consolidation characteristics. However, when the consolidation pressure increases gradually, the final settlement, coefficient of secondary consolidation, and coefficient of consolidation of the clayey soil with the addition of nano-bentonite all show an increasing trend, and the test soil has a larger permeability coefficient under high pressure, which indicates that the addition of nano-bentonite accelerates the drainage consolidation of the clayey soil.

(2) After adding a small amount of nano-bentonite, the clayey soil exhibits different consolidation characteristics. When the nano-bentonite mixing content is $0.5 \%$, the final settlement reaches a maximum, and the final void ratio is the smallest. Under high pressure conditions, the consolidation and permeability coefficients increase with the increase in nano-bentonite mixing content, which indicates that nano-bentonite has modified the consolidation and permeability characteristics of clay.

(3) The mechanism of consolidation and permeability of nano-bentonite mixed soil is mainly manifested in the cementation filling effect of nano-bentonite. The addition of nano-bentonite changes the adhesion and bonding between clay particles. At the same time, the number of voids between clay particles reduces and the size of the voids become smaller. The new cementation between clay particles rearranges the microstructure of the clayey soil. As such, the ability of the clayey soil to resist compression deformation is improved.

Author Contributions: H.-H.Z. designed the overall framework and conceived the idea of this paper, G.C., Y.-N.W. and H.-H.Z. designed the experiments and analyzed the data, B.S. and L.G. provided some suggestions on the structure of the paper, and G.C., Y.-N.W. and H.-H.Z. wrote the paper. All authors have read and agreed to the published version of the manuscript.

Funding: This research was funded by the National Key Research and Development Program of China (No. 2018YFC1505104), National Natural Science Foundation of China (No. 41702347), Natural Science Foundation of Hebei Province, China (No. D2018508107), Key Laboratory of Ministry of Education for Geomechanics and Embankment Engineering, Hohai University (No. 201709), China Postdoctoral Science Foundation (No. 2019M651786), Hebei IoT Monitoring Engineering Technology Research Center (No. 3142018055), and Key Research and Development Program of Hebei Province, China (No. 19270318D).

Acknowledgments: The authors would like to thank Dingfeng Cao, Qing Cheng and Jinghong Wu for their assistance in revising the manuscript.

Conflicts of Interest: The authors declare no conflict of interest. 


\section{References}

1. Vidal, H. The Principle of Reinforced Earth. Highway Res. Rec. 1969, 282, 1-16.

2. Iranpour, B.; Haddad, A. The influence of nanomaterials on collapsible soil treatment. Eng. Geol. 2016, 205, 40-53. [CrossRef]

3. Vardhan, H.; Bordoloi, S.; Garg, A.; Sreedeep, S. Compressive strength analysis of soil reinforced with fiber extracted from water hyacinth. Eng. Comput. 2017, 34, 330-342. [CrossRef]

4. Gao, L.; Hu, G.H.; Xu, N.; Fu, J.Y.; Xiang, C.; Yang, C. Experimental study on unconfined compressive strength of basalt fiber reinforced clay soil. Adv. Mater. Sci. Eng. 2015, 2015, 1-8. [CrossRef]

5. Hejazi, S.M.; Sheikhzadeh, M.; Abtahi, S.M.; Zadhoush, A. Shear modeling of fiber reinforced soil composite on the base of fiber pull-out test. Fiber Polym. 2013, 14, 277-284. [CrossRef]

6. Mirzababaei, M.; Yasrobi, S.S.; Al-Rawas, A.A. Effect of polymers on swelling potential of expansive soils. Proc. Inst. Civil Eng. Ground Improv. 2009, 162, 111-119. [CrossRef]

7. Mirzababaei, M.; Miraftab, M.; Mohamed, M.; Mcmahon, P. Impact of carpet waste fibre addition on swelling properties of compacted clays. Geotech. Geol. Eng. 2013, 31, 173-182. [CrossRef]

8. Soltani, A.; Deng, A.; Taheri, A.; Mirzababaei, M. A sulphonated oil for stabilisation of expansive soils. Int. J. Pavement Eng. 2017, 20, 1285-1298. [CrossRef]

9. Soltani, A.; Deng, A.; Taheri, A.; Sridharan, A. Swell-shrink-consolidation behavior of rubber-reinforced expansive soils. Geotech. Test. J. 2019, 43, 761-788. [CrossRef]

10. Cai, Y.; Shi, B.; Ng, C.W.W.; Tang, C.S. Effect of polypropylene fibre and lime admixture on engineering properties of clayey soil. Eng. Geol. 2006, 87, 230-240. [CrossRef]

11. Tremblay, H.; Duchesne, J.; Locat, J.; Leroueil, S. Influence of the nature of organic compounds on fine soil stabilization with cement. Can. Geotech. J. 2002, 39, 535-546. [CrossRef]

12. Shen, Z.T.; Li, Z.; Alessi, D.S. Stabilization-based soil remediation should consider long-term challenges. Front. Environ. Sci. Eng. 2018, 12, 16. [CrossRef]

13. Hou, D.Y.; Gu, Q.B.; Ma, F.J.; O'Connell, S. Life cycle assessment comparison of thermal desorption and stabilization/solidification of mercury contaminated soil on agricultural land. J. Clean. Prod. 2016, 139, 949-956. [CrossRef]

14. Jahandari, S.; Li, J.; Saberian, M.; Shahsavarigoughari, M. Experimental study of the effects of geogrids on elasticity modulus, brittleness, strength, and stress-strain behavior of lime stabilized kaolinitic clay. GeoResJ 2017, 13, 49-58. [CrossRef]

15. Hollister, P.; Weener, J.W.; Román, C.; Harper, T. Nanoparticles. Technol. White Pap. 2003, 3, 1-11.

16. Al-Salami, A.E.; Morsy, M.S.; Taha, S.; Shoukry, H. Physico-mechanical characteristics of blended white cement pastes containing thermally activated ultrafine nano clays. Constr. Build. Mater. 2013, 47, 138-145. [CrossRef]

17. Gao, L.; Ren, Z.; Yu, X.J. Experimental study of nanometer magnesium oxide-modified clay. Soil Mech. Found. Eng. 2015, 52, 218-224. [CrossRef]

18. Norazlan, K.; Mohd, F.A.; Mazidah, M. The properties of nano-kaolin mixed with kaolin. Electron. J. Geotech. Eng. 2014, 19, 4247-4255.

19. Zaid, H.M.; Mohd, R.T. Effect of nanomaterial treatment on geotechnical properties of a penang soft soil. J. Asian Sci. Res. 2012, 2, 587-592.

20. Zaid, H.M.; Mohd, R.T. A review of stabilization of soils by using nanomaterials. Aust. J. Basic Appl. Sci. 2013, 7, 576-581.

21. Norazlan, K.; Mohd, F.A.; Mazidah, M. Influence of nano-soil particles in soft soil stabilization. Electron. J. Geotech. Eng. 2015, 20, 731-738.

22. Neethu, S.V.; Remya, S. Engineering behaviour of nanoclay stabilized soil. In Proceedings of the Indian Geotechnical Conference: Geotechnical Advances and Novel Geomechanical Application, Roorkee, India, 22-24 December 2013; pp. 22-24.

23. Abdou, M.I.; Al-Sabagh, A.M.; Dardir, M.M. Evaluation of Egyptian bentonite and nano-bentonite as drilling mud. Egypt. J. Pet. 2013, 22, 53-59. [CrossRef]

24. Mostafa, M.; Mohammadreza, N. Investigation of nano-clay effect on geotechnical properties of Rasht clay. Int. J. Adv. Sci. Tech. Res. 2013, 3, 37-46. 
25. Gao, L.; Hu, G.H.; Chen, J.R.; Ren, K.Y.; Zhou, Q.Y.; Yu, X.J. Dynamic properties of carbon-fiber-reinforced clay soil. Soil Mech. Found. Eng. 2018, 55, 317-324. [CrossRef]

26. Gao, L.; Ren, K.Y.; Ren, Z.; Yu, X.J. Study on the shear property of nano-mgo modified soil. Mar. Georesources Geotechnol. 2017, 36, 465-470. [CrossRef]

27. Ng, C.W.W.; Coo, J.L. Hydraulic conductivity of clay mixed with nanomaterials. Can. Geotech. J. 2014, 52, 1-4. [CrossRef]

28. Li, C. Research on the Impact of Nanomaterials for the Silt Electro-Osmotic Consolidation. Master's Thesis, Wu Han Qing Gong University, Wuhan, China, 2014.

29. Wang, L.; Cho, D.W.; Tsang, D.C.; Cao, X.; Hou, D.; Shen, Z.; Alessi, D.S.; Ok, Y.S.; Poon, C.S. Green remediation of as and $\mathrm{pb}$ contaminated soil using cement-free clay-based stabilization/solidification. Environ. Int. 2019, 126, 336-345. [CrossRef]

30. Hou, D.Y.; Al-Tabbaa, A. Sustainability: A new imperative in contaminated land remediation. Environ. Sci. Policy 2014, 39, 25-34. [CrossRef]

31. Hou, D.Y.; Al-Tabbaa, A.; Guthrie, P.; Watanabe, K. Sustainable waste and materials management: National policy and global perspective. Environ. Sci. Technol. 2012, 46, 2494-2495. [CrossRef]

32. Zhang, S.; Yang, X.; Liu, L.; Zheng, K.; Ju, M.; Liu, J. Bisphenol S Adsorption Behavior on Ferralsol and Biochar Modified Soil with Dissolved Organic Matter. Int. J. Environ. Res. Public Health 2019, 16, 764. [CrossRef]

33. GB/T 17296-2009 Classification and Codes for Chinese Soil; Standards Press of China: Beijing, China, 2009; pp. 1-31.

34. Sharma, V.; Vinayak, H.K.; Marwaha, B.M. Enhancing compressive strength of soil using natural fibers. Constr. Build. Mater. 2015, 93, 943-949. [CrossRef]

35. GB/T 50123 - 1999 Standard for Soil Test Method; China Planning Press: Beijing, China, 1999; pp. 74-84.

36. Taha, M.R.; Jawad, I.T.; Majeed, Z.H. Treatment of soft soil with nano-magnesium oxide. In Proceedings of the 5th International Symposium on Nanotechnology in Construction, Chicago, IL, USA, 24-26 May 2015; pp. 1-9.

37. Soltani, A.; Deng, A.; Taheri, A.; Sridharan, A.; Estabragh, A. A Framework for Interpretation of the Compressibility Behavior of Soils. Geotech. Test. J. 2018, 41, 1-16. [CrossRef]

38. Tewatia, S.; Venkatachalam, K. Improved square root of time method to evaluate consolidation test results. Geotech. Test. J. 1997, 20, 121-125.

39. Gibson, R.E.; England, G.L.; Hussey, M.J.L. The theory of one-dimensional consolidation of saturated clays. Can. Geotech. J. 1982, 19, 261-273. [CrossRef]

40. Nishida, Y.; Koike, H.; Nakagawa, S. Coefficient of Permeability of Highly Plastic Clays. In Proceedings of the 4th Budapest Conference on Soil Mechanics and Foundation Engineering, Budapest, Hungary, 12-15 October 1971; pp. 219-224.

41. Ouhadi, V.R.; Noori, A. Impact of Nano-Clay on Consolidation and Permeability Behaviour of Bentonite in the Presence of Heavy Metal Contaminant. Modares Civ. Eng. J. 2013, 13, 1-10.

(C) 2020 by the authors. Licensee MDPI, Basel, Switzerland. This article is an open access article distributed under the terms and conditions of the Creative Commons Attribution (CC BY) license (http://creativecommons.org/licenses/by/4.0/). 